\title{
Serotonin Axons Lose the Ability to Grow Into Fetal Ventral Mesencephalic Grafts Shortly After Birth
}

\author{
Guy Doucet, Abderrahman Mounir, Mariem Chkirate, Annie Vallée and Michel Geffard* \\ Département de Pathologie et Centre de Recherche en Sciences Neurologiques, Faculté de \\ Médecine, Université de Montréal, Montréal, (Québec), Canada, and \\ *Laboratoire d'Immunologie et Pathologie, Universite de Bordeaux II, Bordeaux, France
}

\begin{abstract}
Adult host serotonin (5-HT) neurons display a particularly good capacity to innervate intrastriatal grafts of fetal tissue from several CNS regions $/ 1,2 /$. However, following intrastriatal transplantation of ventral mesencephalic tissue, the 5-HT innervation from adult host brain was found to be very sparse and almost exclusively confined to the borders of the grafts 13/. The present study investigated whether neonatal 5-HT neurons would show a better potential than adult ones for axonal growth into such grafts. Unilateral implantation of dissociated fetal (E14) ventral mesencephalic tissue was carried out in neonatal (P7 or P14) and adult rat neostriatum, previously dopaminedenervated or not by administration of 6hydroxydopamine. All transplants were treated with 1 or $10 \mu \mathrm{M}$ 5,7-dihydroxytryptamine (5,7-
\end{abstract} DHT) in the presence of $50 \mu \mathrm{M}$ benztropine, prior to implantation into recipient brains. The animals were perfusion-fixed 2-6 months later, and the brains processed for dopamine and 5HT immunocytochemistry in alternating $50 \mu \mathrm{m}$ thick vibratome sections. A parallel series of untreated rats was also processed at P7, P14 and P21 for 5-HT immunocytochemistry, to study the normal development of the 5-HT innervation in striatum and ventral mesencephalon. Only grafts clearly distinct from the host parenchyma were included in this study $(\mathrm{n}=23)$. A few grafts (P7 and adult recipients) containing a small number of $5-\mathrm{HT}$ nerve cell bodies (1-5/section) also displayed a rich network of 5-HT axons. In all other cases (P7, P14 and adult recipients), the grafts were totally devoid of 5-HT cell bodies, as assessed by 5-HT immunocytochemistry. In these instances, P14 as well as adult recipient grafts contained very few 5-HT immunopositive axons, which were almost exclusively confined to their periphery. Grafts in $\mathrm{P} 7$ recipients, however, contained many more 5-HT fibers, which were visualized in their core as well as at their periphery. In developing non-grafted rats, 5-HT axons had not yet reached the striatum at P7 (see also 4) and 5-HT immunostaining was still clearly weaker at P21 than in adults. In the mesencephalon and particularly the substantia nigra, the density of 5-HT innervation at P14 was nearly comparable to that of adults.

Several conclusions may be drawn from these observations. First, 5-HT axons are able to grow into fetal ventral mesencephalic grafts, but only at the fetal stage (E14) and until shortly after birth (P7). Second, the loss by 5-HT axons of the ability to grow into fetal ventral mesencephalic tissue after P14 is apparently selective for this tissue, since adult 5-HT axons have been shown in several studies to innervate fetal CNS tissue. It is therefore not the growth potential of these neurons which is modified after birth but their affinity for a specific type of tissue. Third, 5-HT axons have lost most of their ability to innervate ventral mesencephalic tissue at P14 even though they are still growing in the striatum at P21. On the other hand, the 5-HT innervation of substantia nigra at P14 has already reached a density comparable to that of the adult. The loss by intrastriatal 5-HT axons of the ability to grow into ventral mesencephalic grafts seems therefore to correlate better with the development of the midbrain 5-HT innervation. We propose that 5-HT axons bear tissue specific receptors which control their growth in different brain regions. Those receptors normally recognizing ventral mesencephalon would be rapidly modified after birth in such a way that they would no longer promote axonal elongation in this region.

\section{REFERENCES}

1. Lu SY et al. Exp Neurol 1991; 113: 109-130.

2. Wictorin K et al. Neuroscience $1988 ; 27: 547-562$.

3. Doucet G et al. Exp Neurol 1989; 106: 1-19.

4. Lidov HG, Molliver ME. Brain Bull Res 1982; 8: 389 . 430. 

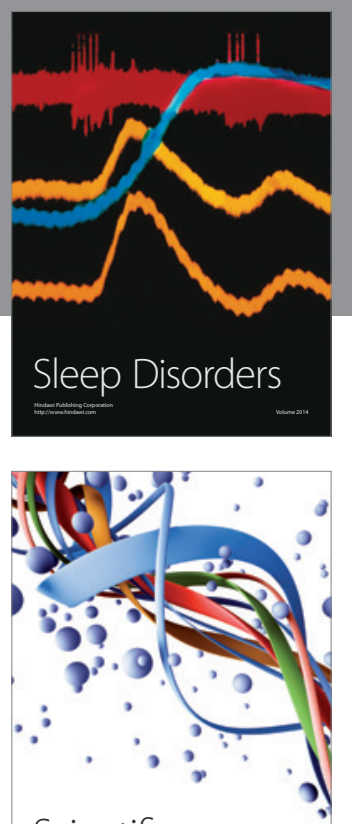

Scientifica
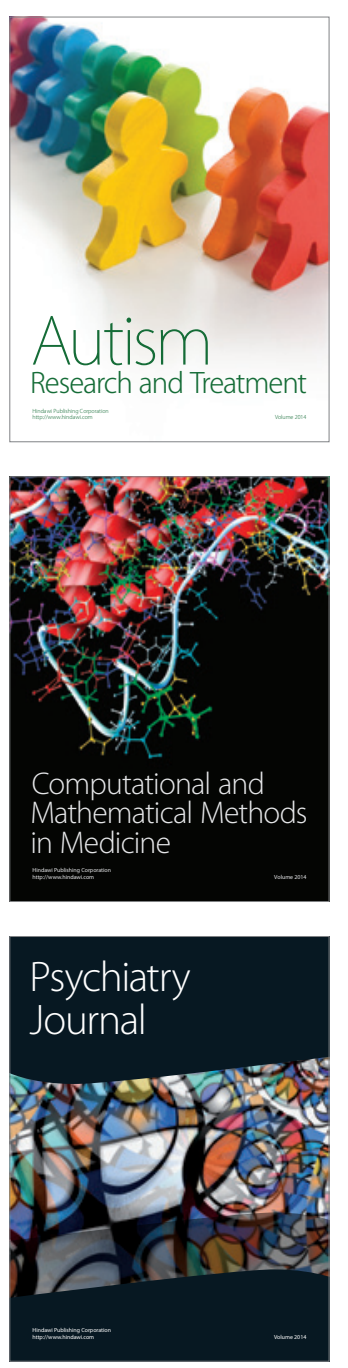
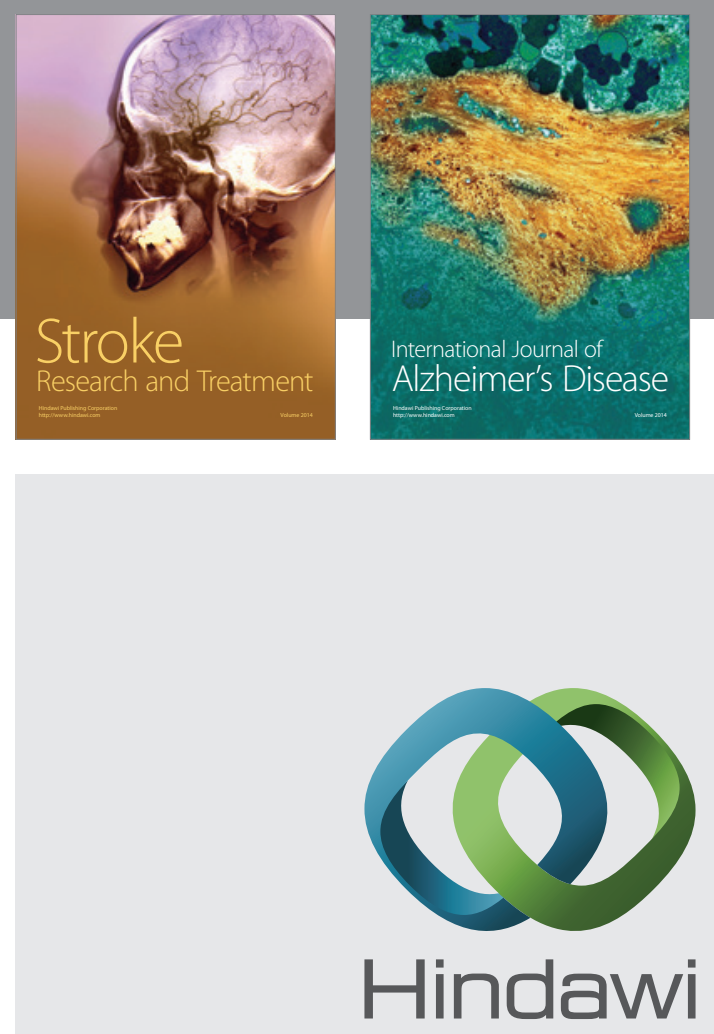

Submit your manuscripts at

http://www.hindawi.com
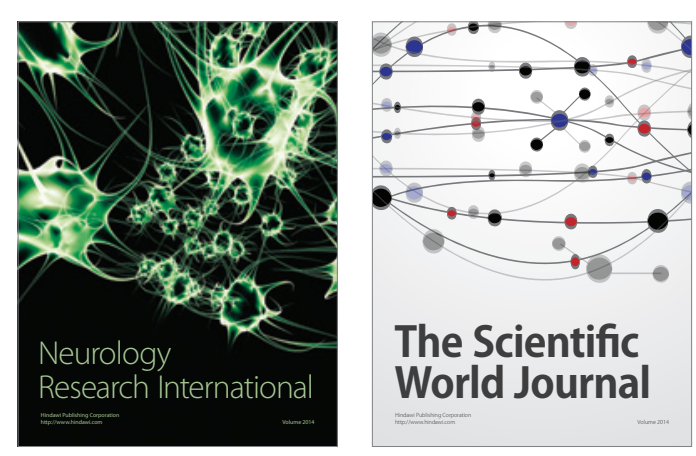

The Scientific World Journal

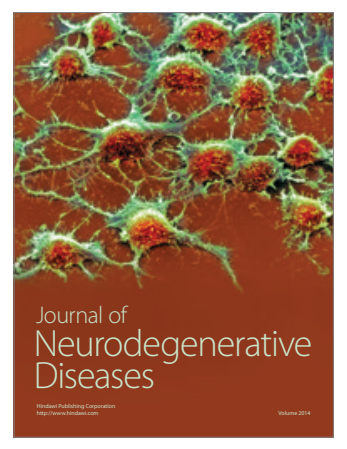

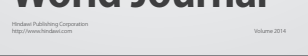

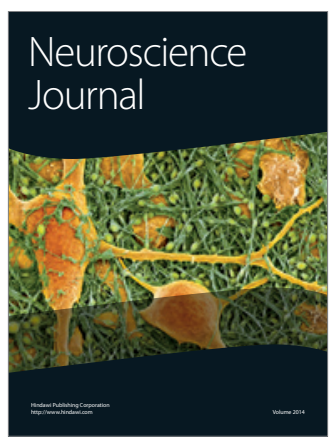

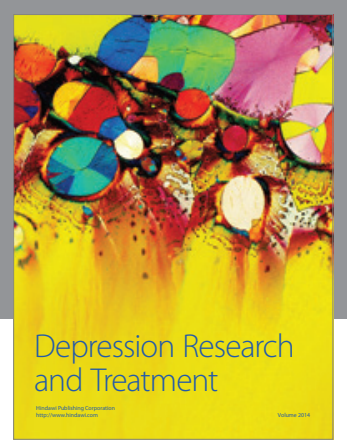
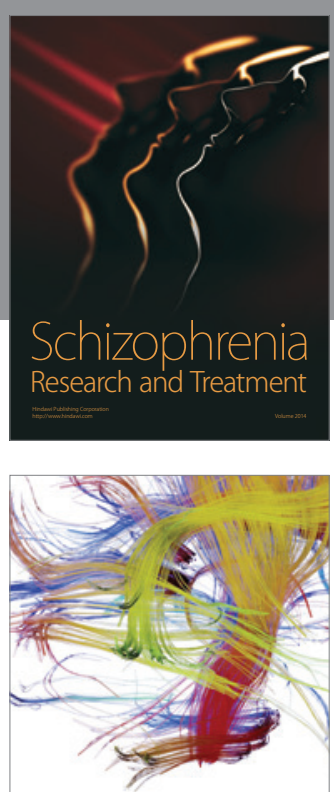

Brain Science

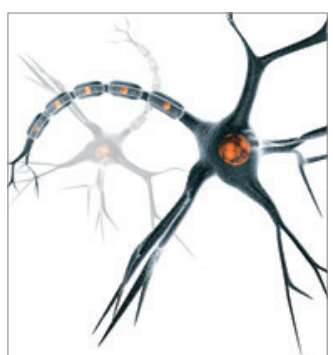

Neural Plasticity
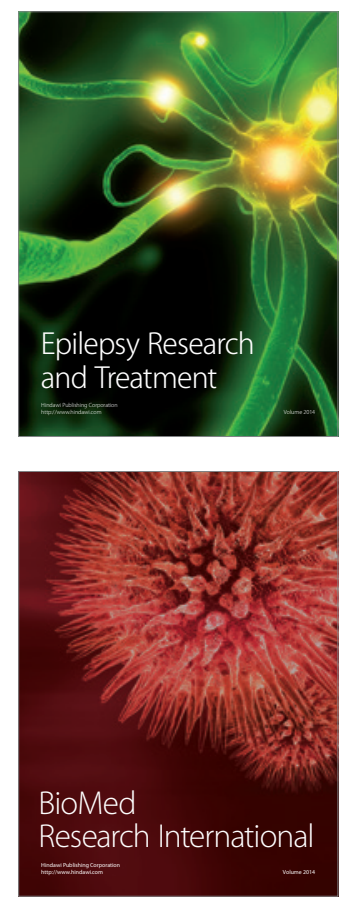

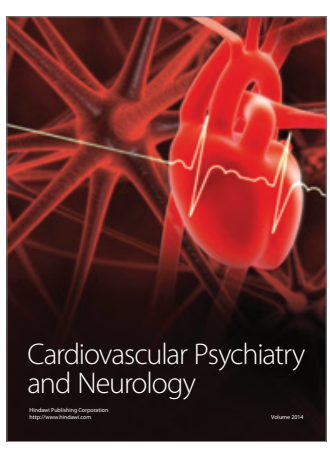

Parkinson's

Disease
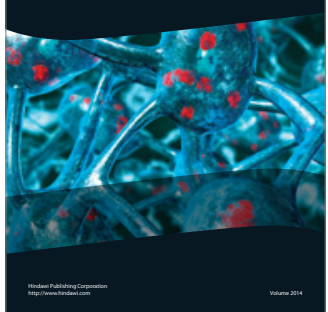